\title{
Longer time after bariatric surgery and sedentary leisure modify anthropometric parameters, body composition and sarcopenic obesity markers in women
}

\author{
Tempos mais longos após cirurgia bariátrica e lazer sedentário modificam \\ parâmetros antropométricos, composição corporal e marcadores de \\ obesidade sarcopênica em mulheres
}

Luzia Jaeger Hintze', Danilo Fernandes da Silva², Josiane Aparecida Alves Bianchini², Rafaela Pilegi Dada², Jessica McNeil', Nelson Nardo Junior ${ }^{2}$

\begin{abstract}
Sarcopenic Obesity is known as a decrease in the quantity and quality of the skeletal muscle mass and increase in fat mass. It can be measured by the residual appendicular skeletal muscle mass (Ap SMM) based on the difference between actual and predicted values. Even though this condition is more common among sedentary elderlies, it may be present in subjects who underwent Bariatric Surgery (BS). We aimed to evaluate the influence of time after BS and physical activity level (PAL) during leisure time on anthropometric parameters, body composition and sarcopenic obesity markers in women. It is a cross-sectional study involving 42 women divided into two groups according to the time since BS and two groups according to PAL. Anthropometric variables, body composition, and sarcopenic obesity markers were assessed. The variables appendicular skeletal muscle mass, height, and fat mass were used to determine sarcopenic obesity markers. Non-parametric numerical tests were used for group comparison and significance level was set at $\mathrm{p}<0.05$. Considering women with sedentary leisure only, those with longer time after BS had higher current body weight and BMI, waist and hip circumference, fat mass, fat-free mass, Ap SMM (equation, residual, and relative) ( $\mathrm{p}<0.05)$. Considering women with longer time after BS only, sedentary ones had higher current body weight and BMI, waist circumference, fat mass, fat-free mass (relative only), Ap SMM (equation and relative) $(p<0.05)$. Our data indicate that longer time after BS and sedentary leisure modify anthropometric parameters, body composition and sarcopenic obesity markers in women.
\end{abstract}

\section{Keywords}

Bariatric Surgery; Body Composition; Sarcopenia; Motor Activity; Obesity.

\section{Resumo}

A Obesidade Sarcopênica é associada à diminuição da quantidade e qualidade da massa muscular esquelética e pelo aumento na massa gorda. Ela pode ser medida pela massa muscular esquelética apendicular (Ap MME) baseada na diferença entre os valores reais e preditos. Mesmo sendo mais comum em idosos sedentários, esta condição pode ser verificada em indivíduos submetidos à Cirurgia Bariátrica (CB). O objetivo do estudo foi avaliar a influência do tempo de $C B$ e nível de actividade física (NAF) durante o lazer em parâmetros antropométricos, composição corporal e marcadores de obesidade sarcopênica em mulheres. Trata-se de um estudo transversal, envolvendo 42 mulheres, divididos em dois grupos de acordo com o tempo de $C B$ e dois grupos de acordo com o NAF. Variáveis antropométricas, composição corporal e marcadores de obesidade sarcopênica foram avaliados. As variáveis massa muscular esquelética appendicular, altura e massa gorda foram usadas para determinar marcadores de obesidade sarcopênica. Testes numéricos não-paramétricos foram usados para comparação de grupos e o nivel de significância foi estabelecido em $p<0,05$. Considerando as mulheres sedentárias no lazer apenas, aquelas com maior tempo após a CB tiveram maior peso e IMC atuais, circunferência de cintura e quadril, massa gorda, massa livre de gordura, Ap MME (equação, residual e relativa) ( $p<0.05)$. Considerando as mulheres com maior tempo após a CB apenas, as sedentárias tiveram maior peso e IMC atual, circunferência de cintura, massa gorda, massa livre de gordura (relativa apenas), Ap MME (equação e residual) ( $p<0.05)$. Nossos achados indicam que maior tempo após $C B$ e lazer sedentário modificaram parâmetros antropométricos, composição corporal e marcadores de obesidade sarcopênica em mulheres.

\section{Palavras-chave}

Cirurgia bariátrica; Composição corporal; Sarcopenia; Atividade motora; Obesidade. 


\section{Introduction}

Important changes in body composition may occur with aging, such as reductions in the quantity and quality of Skeletal Muscle Mass (SMM) and the preservation or increase in fat mass. This loss in SMM can be unnoticeable in obese people, unless there is clear functional loss of muscle strength. This condition is known as "sarcopenic obesity"1-3. In addition to the impairment of functional capacity", there are other health consequences related to sarcopenic obesity. One of these effects is an increased risk of developing type 2 diabetes mellitus ${ }^{5}$, increased levels of triglycerides, metabolic syndrome and cardiovascular disease $e^{6-8}$.

Many times, the cause of sarcopenia, as well as obesity, is multifactorial. Thus, there are many criteria that classify sarcopenic obesity ${ }^{2,9}$. Aging is typically the major cause; however, other factors may interfere with the development of this condition. These factors may include sedentary lifestyle, low consumption and absorption of nutrients, low levels of vitamin $\mathrm{D}$, use of medications that cause anorexia and smoking ${ }^{2,5}$.

Sedentary lifestyle is an important risk factor related to weight gain and the decrease in $\mathrm{SMM}^{10}$. Obese people tend to be less physically active when compared with normal weight people, which could contribute to decreased mugenescle strength ${ }^{11}$. Thus, general muscle loss can lead to a reduction in Resting Metabolic Rate and the reduction of energy expenditure during exercise and daily physical activities, which may further aggravate the sedentary state, and the accumulation of fat mass ${ }^{2,12}$.

The prevalence of morbid obesity $\left(\mathrm{BMI} \geq 40 \mathrm{~kg} / \mathrm{m}^{2}\right)$ is around $3 \%$ in the Brazilian population and the Brazilian Unified Health System has provided over 50,000 bariatric surgeries up to $2014^{13}$. Although the prevalence is lower than the United States $(6.6 \%)^{14}$, these data are alarming. As consequences of BS, previous studies showed that it is linked to a drastic reduction in food intake and food absorption as well as protein and micronutrient absorption what could differentiate sarcopenic obesity from cachexia syndrome, and are risk factors for the onset of the disease $^{15}$. It demonstrates a possible association between BS and sarcopenic obesity. They observed that the risks of BS in individuals over 60 years outweigh their benefits, because the resulting weight loss reduced fat mass, but also SMM and bone mineral density, thus increasing the risk of adverse consequences for health of elderly obese individuals.

We aimed to evaluate the influence of time after BS and physical activity level (PAL) during leisure time on anthropometric parameters, body composition and sarcopenic obesity markers in women. Our hypothesis was that greater elapsed time since the operation and sedentary state after the BS would be associated with poorer anthropometric parameters, body composition, and markers of sarcopenic obesity.

\section{Methods}

\section{Subjects}

The study included 42 women who underwent BS, matching the following inclusion criteria: bariatric surgery (Roux en Y gastric bypass) conducted through the Brazilian Unified Health System between 1999 and 2010, and age between 26 and 75-year old. A list of names and phone numbers of 209 patients who underwent BS between 1999 and 2010 were obtained from the University Hospital and the Local Health Department of the city. Our research team contacted the patients to invite them to participate in the study. From that list, only 71 individuals were located. Among them, 21 had no interest in participating in the survey or did not attend their scheduled session, even after re-scheduling on numerous occasions. In 
addition, posters publicizing the project were distributed at the University campus and in health facilities around our city to recruit more patients. With this release, two more subjects who met the criteria of the operated group were included in the survey (total $n=52$ ). Due to the small sample size of men who sought to be part of the study (10 participants), and the lack of an age-specific equation to determine sarcopenic obesity for this sex, only women were included in the present analysis.

This study is part of a major research which was approved by 'Comitê Permanente de Ética em Pesquisa com Seres Humanos (COPEP) - Universidade Estadual de Maringá' - protocol 412/2008, entitled Assessment of Bariatric Surgery: retrospective study. Before the assessments, all the subjects read and signed the consent form of the study which is in conformity with the Brazilian law.

\section{Instruments and Measurement Protocols}

As the first step of the study, subjects completed an anamnesis form. This form contains questions related to BS (date of procedure, surgical technique, the smallest weight achieved after surgery), the continuous use of medications by the patient after BS and some specific questions in order to conduct an evaluation by dual-energy X-ray absorptiometry. According to the Brazilian Society for Clinical Densitometry ${ }^{16}$, the use of dual-energy $\mathrm{X}$-ray absorptiometry is not recommended for pregnant women and individuals who have done some $\mathrm{x}$-ray contrast / barium or nuclear medicine two weeks prior to the test.

If the patient did not know the name of the surgical technique performed, a description about the different procedures used by the Brazilian Unified Health System was offered to them, thus allowing them to indicate the description of the procedure which best described their undergone operation. The present study included only patients who reported being subjected to combined techniques (restrictive plus disarbsorptive, Roux en Y gastric bypass).

\section{Anthropometric and Body Composition Assessment}

Body weight and height were assessed in order to calculate BMI (BMI = weight $\left.\mathrm{kg} / \mathrm{m}^{2}\right)$. The measurement of weight was done on an electronic scale with a capacity of 300 $\mathrm{kg}$ and $0.05 \mathrm{~kg}$ precision. Height was measured with a stadiometer to the nearest $0.1 \mathrm{~cm}$. All circumferences were measured with a tape to nearest $0.01 \mathrm{~cm}$. The smallest portion at the abdominal area and the biggest portion of the gluteal area were considered as the anatomical references to the waist (WC) and hips circumference (HC) measures, respectively.

The assessment of body composition was done by X-ray Dual Energy Absorptiometry (GE Lunar Prodigy Primo model; Encore software version 13.50). This method consists of a high-tech procedure that allows the quantification of Fat Mass (FM), Fat Free Mass (FFM), and Bone Mineral Content (BMC) of the whole body and specific regions. It also has wide applicability primarily due to the rapid assessment, the low doses of radiation emitted (between 0.05 mrem to $1.5 \mathrm{mrem}$ ) and the production of reliable fat mass and bone mineral content results. Assessment of body composition by X-ray Dual Energy Absorptiometry assumes that the areas of bone and soft tissues can be penetrated by a depth of approximately $30 \mathrm{~cm}$ by two distinct peaks of energy from an isotopes source of high affinity. The penetration of the two peaks of energy $(40 \mathrm{kV}$ and $70 \mathrm{kV})$ in the muscle; fat and bone promote an attenuation of X-rays, which then is analyzed by a scintillation detector. The decay constant for fat mass is 1.21 while for lean body mass is 1.39 .

For the assessment of body composition of the entire body, the subjects were 
placed in supine position, with the palms facing down, in the center of the scanning area. A professional checked if all parts of the body were within the scanning area. Patients were instructed to do not move until the end of the assessment. We placed hook-and-loop fasteners straps at the knees and ankles, as recommended by the manufacturers of the equipment.

\section{Evaluation of sarcopenic obesity}

For the evaluation of sarcopenic obesity, the model developed by Newman et al. ${ }^{17}$ and adapted by Oliveira et al. ${ }^{18}$ was used to obtain numerical results. This regression model proposes an adjustment of SMM by fat mass and stature. The difference between the value generated by regression and the Appendicular SMM measured by $\mathrm{X}$-ray Dual Energy Absorptiometry (i.e., the residual value) was used as a diagnostic criterion for sarcopenic obesity. The following formula according to Oliveira et al. ${ }^{18}$ in Brazilian women with a wide age range were used to assess Appendicular SMM:

Appendicular SMM $=-14.529+(17.989 \times$ height $(\mathrm{m}))+(0.1307 \times \mathrm{FM}(\mathrm{kg}))$

To classify numerical data obtained based on Oliveira et al..$^{18}$ formula, we used the cut-off points proposed by the authors $(-3.4$ based on values that were equal to or below 2 standard deviations of the mean in the reference sample), which was proposed specifically for women in an age range of 18-40 years. Thus, older women who presented residual $\leq 3.4$ were considered to have sarcopenic obesity ${ }^{18}$. Sarcopenic obesity markers based on Ap SMM for the numerical analysis were considered: Ap SMM (absolute, relative, residual, and equation [predicted]).

\section{Assessment of Time since BS}

The subjects included in the study $(n=42)$ were divided in two groups according to time since BS: patients operated between 36 and 96 months $(n=18)$ and patients operated for over than 96 months $(n=24)$. This cut off point was set based on $\mathrm{O}^{\prime}$ Brien et al. ${ }^{19}$. According to the authors, this surgery procedure leads to great weight changes in the first two years, and then weight tends to be stable from the third to the eighth year after BS. After this, the tendency is to reduce the percentage of excess weight loss ${ }^{19}$.

\section{Assessment of Physical Activity}

The evaluation of the physical activity level (PAL) was done with a questionnaire proposed by Larsson et al. ${ }^{20}$, validated for men and women with different BMI ranges. The questionnaire contains only two questions: one related to PAL at work and another on leisure time. The questions of leisure time use a Likert scale rated from 1-4, where "1" represents a low PAL, " 2 " represents an average PA level and " 3 " and " 4 " represent very high PA levels while the questions of PAL at work are answered in a scale from $0-4$, where the additional number (i.e., 0 ) represents sedentary work. Subjects were instructed to mark only one answer for each question, calculating the mean PAL if this was to vary much across the different months of the year. For data analysis, the responses of each question were divided into two categories (a) less active and (b) more active. At one point, referring to the PAL at leisure, were considered less active people who pointed out the number ' 1 ' and most active people who reported the numbers ' 2,3 or 4 ' in the survey ${ }^{21}$. Referring to the PAL at work, were considered less active participants who pointed out the numbers ' 0 ', ' 1 ' and ' 2 ' and most active who have chosen the numbers ' 3 ' and ' 4 '21. 


\section{Statistical Procedures}

No sample size calculation was performed given the specificity of the population. The descriptive analysis included measures of central tendency (mean and median), dispersion (standard deviation and interquartile range), and absolute and relative frequency. The Shapiro-Wilk test was used to check for normality. Due to the small sample size, all data was analyzed only with non-parametric numerical tests. Mann-Whitney test was used for group comparisons and Spearman test for correlations. Statistical significance was set at $\mathrm{p}<0.05$.

\section{Results}

The study included a total of 42 women aged between 26 and 75 years. From all the participants, 9 (21.4\%) presented sarcopenic obesity. Regarding PAL at leisure, 27 (64.3\%) were classified as sedentary and only 1 (2.4\%) had an active work. Given that, we did not perform numerical inferential analysis for PAL at work. Eighteen (42.9\%) women performed BS 36-96 months before the assessment while 24 (57.1\%) performed for longer than 96 months.

Table 1 presents the values indicative of central tendency and dispersion of age, time after BS, anthropometric variables, body composition, and sarcopenic obesity markers of individuals with and without sarcopenic obesity, as well as the result of comparison tests between the groups. Women with sarcopenic obesity showed increased current body weight and BMI, WC, HC, fat mass (absolute and relative), and reduced percentage FFM, Ap SMM (equation, residual, and relative). We also correlated age and the residual Ap SMM and the Spearman coefficient of correlation was $0.004(\mathrm{p}=0.982)$.

TABLE 1 - Anthropometric, time after BS, body composition, and sarcopenic obesity markers of subjects with sarcopenic obesity vs subjects without sarcopenic obesity.

\begin{tabular}{|c|c|c|c|}
\hline Variables & No sarcopenic obesity ( $n=33$ ) & Sarcopenic Obesity $(n=9)$ & $P$ \\
\hline Age (years) & $53.9[42.6-58.6]$ & $52.4[45.7-55.8]$ & 0.759 \\
\hline Time after BS (months) & $96[57.5-113.5]$ & $102[98.5-136.5]$ & 0.238 \\
\hline Weight before surgery (kg) & $125[111-140]$ & $130[118-146.5]$ & 0.304 \\
\hline BMI before surgery $\left(\mathrm{Kg} / \mathrm{m}^{2}\right)$ & $50.1[44.2-53.8]$ & $50.6[45.5-54.9]$ & 0.890 \\
\hline Current weight (Kg) & $83.4[72.6-90.8]$ & $96.8[90-117]$ & $0.001^{*}$ \\
\hline Current BMI $\left(\mathrm{Kg} / \mathrm{m}^{2}\right)$ & $32.2[28.5-36.5]$ & $38.3[34.9-43.7]$ & $0.007^{*}$ \\
\hline WC $(\mathrm{cm})$ & $92[80.7-104]$ & $103[96-115]$ & $0.009^{*}$ \\
\hline $\mathrm{HC}(\mathrm{cm})$ & $116[106.5-112.3]$ & $125[116-141]$ & $0.019^{*}$ \\
\hline Fat mass (Kg) & $38.5[28.6-44.2]$ & $51.6[46.5-60.7]$ & $<0.001^{*}$ \\
\hline$\%$ Fat & $48[41.9-51]$ & $55.5[53.5-56.4]$ & $<0.001^{*}$ \\
\hline FFM (Kg) & $41.4[37.9-43.4]$ & $40.1[38.1-51.9]$ & 0.613 \\
\hline$\%$ FFM & $50.7[47.4-56.1]$ & $43.1[42.7-45.3]$ & $<0.001^{*}$ \\
\hline $\mathrm{BMC}(\mathrm{Kg})$ & $2.3[2.0-2.7]$ & $2.7[2.1-2.7]$ & 0.434 \\
\hline Ap SMM (Kg) - DEXA & $17.3[16.2-18.6]$ & $16.3[14.1-17.5]$ & 0.154 \\
\hline Ap SMM (kg) - equation & $18.7[17.6-19.6]$ & $20.9[20.2-22.9]$ & $0.001^{*}$ \\
\hline Ap SMM Residual** & $-1.17[-2.30--0.27]$ & $-4.71[-6.14--4.15]$ & $<0.001^{*}$ \\
\hline$\%$ Ap SMM & $22.2[20.0-24.5]$ & $17.2[14.8-17.9]$ & $<0.001^{*}$ \\
\hline
\end{tabular}

BS: Bariatric Surgery; BMI: Body Mass Index; WC: waist circumference; HC: hip circumference; FFM: fat free mass; BMC: Bone Mineral Content; Ap SMM: Appendicular skeletal muscle mass. *Significant differences in the Mann-Whitney non-parametric test $(p<0.05)$. ${ }^{* * A p}$ SMM $(k g)$ DEXA - Ap SMM $(\mathrm{kg})$ - Equation. 
Table 2 shows the comparison between women with shorter time after BS versus women with longer time after BS for anthropometric parameters, body composition, and sarcopenic obesity markers according to PAL. Interestingly, women with shorter time after BS had better anthropometric parameters, body composition and sarcopenic obesity markers only for the sedentary ones. For active women, no differences were found between patients operated for longer (>96 months) and shorther periods (36 to 96 months).

TABLE 2 - Comparison between women with shorter time after BS versus women with longer time after BS for anthropometric parameters, body composition, and sarcopenic obesity markers according to PAL $(n=42)$.

\begin{tabular}{|c|c|c|c|}
\hline \multicolumn{4}{|c|}{ Sedentary leisure; $n=27$} \\
\hline Variables & $\leq 96$ months after $B S(n=12)$ & $>96$ months after $B S(n=15)$ & $P$ \\
\hline Current weight (Kg) & $76.3[72.4-86.2]$ & $96.8[87.2-105.5]$ & $<0.001^{*}$ \\
\hline Current BMI $\left(\mathrm{Kg} / \mathrm{m}^{2}\right)$ & $31.9[28.6-33.9]$ & $38.3[36.4-44.6]$ & $0.001^{*}$ \\
\hline WC (cm) & $92.2[81.3-95.5]$ & $111[101-114]$ & $<0.001^{*}$ \\
\hline $\mathrm{HC}(\mathrm{cm})$ & $114[108-119.8]$ & 125 [116 - 139] & $0.005^{*}$ \\
\hline Fat mass $(\mathrm{Kg})$ & $35.5[29.5-40]$ & $48.7[44.3-54.2]$ & $<0.001^{*}$ \\
\hline$\%$ Fat & $47.3[43.2-50.3]$ & $53.1[48.3-55.9]$ & $0.008^{*}$ \\
\hline FFM (Kg) & $39.6[35.3-41.8]$ & $42.7[41.4-50.7]$ & $0.005^{*}$ \\
\hline$\%$ FFM & $51.2[48.1-54.7]$ & $45.4[43.1-50.3]$ & $0.011^{*}$ \\
\hline $\mathrm{BMC}(\mathrm{Kg})$ & $2.33[2.07-1.82]$ & $2.31[2.03-2.70]$ & 0.661 \\
\hline Ap SMM (Kg) - DEXA & $17[15.1-18.4]$ & $17.5[16.3-18.7]$ & 0.661 \\
\hline Ap SMM (kg) - equation & $18.6[17.2-19.4]$ & $20.4[19.7-20.9]$ & $0.001^{*}$ \\
\hline Ap SMM Residual** & $-1.20[-2.28-0.03]$ & $-2.80[-4.96--0.55]$ & $0.047^{*}$ \\
\hline$\%$ Ap SMM & $22.3[21.5-24]$ & $19[16.6-20.1]$ & $<0.001^{*}$ \\
\hline \multicolumn{4}{|c|}{ Regular moderate exercise; $n=15$} \\
\hline Variables & $\leq 96$ months after BS $(n=6)$ & $>96$ months after $B S(n=9)$ & $P$ \\
\hline Current weight (Kg) & $76.3[54.0-87.5]$ & $81.8[72.3-92.3]$ & 0.289 \\
\hline Current BMI $\left(\mathrm{Kg} / \mathrm{m}^{2}\right)$ & $29.1[23.0-33.3]$ & $34.9[27.8-36.8]$ & 0.157 \\
\hline WC (cm) & $79[78.5-91.5]$ & $91[83.9-99.5]$ & 0.139 \\
\hline $\mathrm{HC}(\mathrm{cm})$ & $110.5[86-122]$ & $119[102-124]$ & 0.376 \\
\hline Fat mass (Kg) & $33.6[14.9-43.5]$ & $40.0[28.3-44.5]$ & 0.456 \\
\hline$\%$ Fat & $45.6[28.8-53]$ & $48[38.9-51.8]$ & 0.953 \\
\hline FFM (Kg) & $39.4[36.2-40.4]$ & $42.1[37.9-46.7]$ & 0.239 \\
\hline$\%$ FFM & $52.3[45.2-68.7]$ & $50.7[47-59]$ & 1.000 \\
\hline $\mathrm{BMC}(\mathrm{Kg})$ & $2.86[1.93-3.50]$ & $2.27[2.05-2.81]$ & 0.289 \\
\hline Ap SMM (Kg) - DEXA & $17.1[15.6-17.4]$ & $18.2[15.5-19.6]$ & 0.409 \\
\hline Ap SMM (kg) - equation & $19.1[15-20.3]$ & $18.5[17.5-19.5]$ & 0.906 \\
\hline Ap SMM Residual** & $-1.76[-3.11-0.20]$ & $-0.88[-2.75-0.52]$ & 0.556 \\
\hline$\%$ Ap SMM & $23[19.8-28.4]$ & $22.6[19.1-27.9]$ & 0.724 \\
\hline
\end{tabular}

BMI: Body Mass Index; WC: waist circumference; HC: hip circumference; FFM: fat free mass; BMC: Bone Mineral Content; Ap SMM: Appendicular skeletal muscle mass. *Significant differences in the Mann-Whitney non-parametric test $(p<0.05) .{ }^{* * A p ~ S M M ~}(\mathrm{~kg})$ DEXA - Ap SMM (kg) - Equation.

Considering only those individuals who underwent BS between 36 and 96 months, no differences were found for the numerical parameters analyzed. However, for subjects who underwent BS for more than 96 months, sedentary women had poorer anthropometric parameters, body composition and sarcopenic obesity markers (table 3 ). 
TABLE 3 - Comparison between women with sedentary versus women with regular moderate exercise at leisure for anthropometric parameters, body composition, and sarcopenic obesity markers according to time after BS $(n=42)$.

\begin{tabular}{|c|c|c|c|}
\hline \multicolumn{4}{|c|}{$\leq 96$ months; $\mathrm{n}=18$} \\
\hline Variables & Sedentary leisure $(n=12)$ & Regular moderate exercise $(n=6)$ & $P$ \\
\hline Current weight (Kg) & $76.3[72.4-86.2]$ & $76.3[54.0-87.5]$ & 0.606 \\
\hline Current BMI $\left(\mathrm{Kg} / \mathrm{m}^{2}\right)$ & $31.9[28.6-33.9]$ & $29.1[23.0-33.3]$ & 0.223 \\
\hline$W C(\mathrm{~cm})$ & $92.2[81.3-95.5]$ & $79[78.5-91.5]$ & 0.082 \\
\hline $\mathrm{HC}(\mathrm{cm})$ & $114[108-119.8]$ & $110.5[86-122]$ & 0.638 \\
\hline Fat mass (Kg) & $35.5[29.5-40]$ & $33.6[14.9-43.5]$ & 0.851 \\
\hline$\%$ Fat & $47.3[43.2-50.3]$ & $45.6[28.8-53]$ & 0.925 \\
\hline FFM (Kg) & $39.4[36.2-40.4]$ & $39.4[36.2-40.4]$ & 0.925 \\
\hline$\%$ FFM & $51.2[48.1-54.7]$ & $52.3[45.2-68.7]$ & 0.925 \\
\hline $\mathrm{BMC}(\mathrm{Kg})$ & $2.33[2.07-1.82]$ & $2.86[1.93-3.50]$ & 0.399 \\
\hline Ap SMM (Kg) - DEXA & $17.1[15.6-17.4]$ & $17.1[15.6-17.4]$ & 0.779 \\
\hline Ap SMM (kg) - equation & $18.6[17.2-19.4]$ & $19.1[15-20.3]$ & 0.454 \\
\hline Ap SMM Residual** & $-1.20[-2.28-0.03]$ & $-1.76[-3.11-0.20]$ & 0.399 \\
\hline$\%$ Ap SMM & $22.3[21.5-24]$ & $23[19.8-28.4]$ & 0.779 \\
\hline \multicolumn{4}{|c|}{$>96$ months; $n=24$} \\
\hline Variables & Sedentary leisure $(n=15)$ & Regular moderate exercise $(n=9)$ & $P$ \\
\hline Current weight (Kg) & $96.8[87.2-105.5]$ & $81.8[72.3-92.3]$ & $0.009^{*}$ \\
\hline Current BMI (Kg/m²) & $38.3[36.4-44.6]$ & $34.9[27.8-36.8]$ & $0.011^{*}$ \\
\hline$W C(\mathrm{~cm})$ & $111[101-114]$ & $91[83.9-99.5]$ & $0.001^{*}$ \\
\hline $\mathrm{HC}(\mathrm{cm})$ & 125 [116 - 139] & 119 [102 - 124] & 0.068 \\
\hline Fat mass $(\mathrm{Kg})$ & $48.7[44.3-54.2]$ & $40.0[28.3-44.5]$ & $0.004^{*}$ \\
\hline$\%$ Fat & $53.1[48.3-55.9]$ & $48[38.9-51.8]$ & $0.022^{*}$ \\
\hline FFM (Kg) & $42.1[37.9-46.7]$ & $42.1[37.9-46.7]$ & 0.222 \\
\hline$\%$ FFM & $45.4[43.1-50.3]$ & $50.7[47-59]$ & $0.030^{*}$ \\
\hline $\mathrm{BMC}(\mathrm{Kg})$ & $2.31[2.03-2.70]$ & $2.27[2.05-2.81]$ & 0.835 \\
\hline Ap SMM (Kg) - DEXA & $18.2[15.5$ - 19.6] & $18.2[15.5-19.6]$ & 0.976 \\
\hline Ap SMM (kg) - equation & $20.4[19.7-20.9]$ & $18.5[17.5-19.5]$ & $0.016^{*}$ \\
\hline Ap SMM Residual** & $-2.80[-4.96--0.55]$ & $-0.89[-2.75-0.52]$ & 0.069 \\
\hline$\%$ Ap SMM & $19[16.6-20.1]$ & $22.6[19.1-27.9]$ & 0.009 \\
\hline
\end{tabular}

BMI: Body Mass Index; WC: waist circumference; HC: hip circumference; FFM: fat free mass; BMC: Bone Mineral Content; Ap SMM: Appendicular skeletal muscle mass. *Significant differences in the Mann-Whitney non-parametric test $(p<0.05) .{ }^{* *}$ Ap SMM (kg) DEXA - Ap SMM (kg) - Equation.

Based on table 2 and 3, we showed that the influence of time after bariatric surgery on the numerical parameters, especially in the markers of sarcopenic obesity, is only observed in sedentary patients. Similarly, the influence of PAL is only observed in patients with longer time after BS.

\section{Discussion}

We evaluated the influence of time after BS and physical activity level (PAL) during leisure time on anthropometric parameters, body composition and sarcopenic obesity markers in women.

The occurrence of bariatric surgery was presented in $21.4 \%$ in women who underwent BS in the present study. Considering women with sedentary leisure only, those with longer time after BS had higher current body weight and BMI, waist 
and hip circumference, fat mass, fat-free mass, Ap SMM (equation, residual, and relative). Considering women with longer time after BS only, sedentary ones had higher current body weight and BMI, waist circumference, fat mass, fat-free mass (relative only), Ap SMM (equation and relative).

The prevalence of sarcopenic obesity observed in our study was similar to that found by Oliveira et al. ${ }^{18}$ who studied women aged 66.8 (5.6) years (19.80\%). Our numbers were still higher compared to other studies, such as those reported by Newman et al. ${ }^{17}$ whose results were a prevalence of $21.7 \%$ among women aged 70 to 79 years. It is important to note that the average age of these participants is higher compared to the age average of the participants in the present study, which is 49.72 (10.29) years. Moreover, they had not undergone to BS.

Some authors point to a decrease in SMM and Ap SMM as age increases ${ }^{11}$, and this is an important factor associated with sarcopenic obesity. In our study, age was not significantly different between sarcopenic and non-sarcopenic groups and did not correlated with residual Ap SMM. However, a significantly lower sarcopenic obesity markers (i.e., Ap SMM measured as predicted, relative and residual) in individuals with sarcopenic obesity was observed, indicating that other variables, eg. time after BS and PAL, may also play a role in the onset of sarcopenic obesity.

To our knowledge, no study mentioned any potential influence of PAL and time after BS on anthropometric parameters, body composition, and sarcopenic obesity markers in women who underwent this surgical procedure. Although the benefits of physical activity in order to prevent sarcopenic obesity are well discussed in the literature ${ }^{2,8,9}$, the present study is the first to show that sarcopenic obesity markers are reduced in patients who underwent BS for longer periods (>96 months).

Freire et al. ${ }^{23}$ demonstrated that subjects who underwent BS had a significant increase in their body weight 5 years after the surgical procedure. One possible factor that explained this increase was the sedentary lifestyle after the BS, as well as the lack of proper counselling regarding eating and exercise behaviour following the operation. Thus, patients may be likely to return to their unhealthy habits after $\mathrm{BS}^{24}$.

Silver et al. ${ }^{25}$ showed that only $17.9 \%$ of operated patients were engaged in physical activity after two years since BS, while $82.1 \%$ of their sample had a moderate level of physical activity. It reinforced the importance of keeping high PAL to prevent weight regain. Adopting a high PAL after BS is extremely important since it helps in the preservation of lean tissue and also contributes to the maintenance of the amount of excess weight loss ${ }^{26,27}$. In the present study, we found that only in patients who underwent BS over 96 months prior to measurements, sedentary leisure negatively influenced anthropometric parameters, body composition, and more importantly, markers of sarcopenic obesity.

If PAL is low after BS, we can speculate that a longer time period after the procedure may lead to greater weight regain and consequently, will negatively influence health parameters. According to Antonini et al. ${ }^{28}$, in operated patients, a greater time elapsed since the operation was associated with poor eating and physical activity behaviors. These patients with low adhesion to eating and exercise behaviors also presented higher BMI than the group with greater adhesion.

Despite the important results, there are some limitations in this study. We had a small sample size, however, this is a very specific population related to the Brazilian unified health system, and the difficulty of follow up patients may have hindered their return to the study. Furthermore, this is a cross-sectional analysis so we do not know the degree of change in FM since BS across the years after the BS. Second, physical activity and sedentary state were evaluated via self-report- 
ed measurements. It may be useful to assess physical activity with more accurate methods (i.e., accelerometers), in this population in the future. Moreover, medical records could not be included in the study considering that they had several missing information or were unreadable, so all the data related to the surgery was self-reported by the patient, which may represent a limitation as well. Finally, we did not measure functional loss (e.g., muscle strength) as a proxy for sarcopenic obesity and we did not control for other factors associated with sarcopenia, such as pre-cachexia or cachexia (anorexia, increased inflammatory markers, and severe body weight, muscle and fat mass loss). However, due to the elevated percentage body fat and the lack of great or total appetite reduction in the last month (non-reported data), especially in the group with sarcopenic obesity, its presence seems to be unlikely.

Our data indicate that longer time after BS and sedentary leisure modify anthropometric parameters, body composition and sarcopenic obesity markers in women. We suggest that future studies should analyze the effects of behavioral-based interventions/counselling in operated subjects, and if these types of intervention may decrease the influence of sedentary behaviours on markers of sarcopenic obesity, mainly in long-term.

\section{Funding}

This study was supported by Financiadora de Estudos e Projetos (FINEP), Brazil (Reference number: FINEP 1862/07).

\section{Contributors}

All authors participated in the design, analysis, data interpretation, article writing, critical review and final approval of the version to be published.

\section{References}

1. Cetin DC, Nasr G. Obesity in the elderly: more complicated than you think. Cleve Clin J Med. 2014; 81(1):51-61.

2. Cruz-Jentoft AJ, Baeyens JP, Bauer JM, Boirie Y, Cederholm T, Landi F, et al. Sarcopenia: European consensus on definition and diagnosis Report of the European Working Group on Sarcopenia in Older People. Age Ageing. 2010;39(4):412-23.

3. Narici MV, Maffulli N. Sarcopenia: characteristics, mechanisms and functional significance. Br Med Bull. 2010;95:139-59.

4. Mathus-Vliegen EM, Obesity Management Task Force of the European Association for the Study of Obesity. Prevalence, pathophysiology, health consequences and treatment options of obesity in the elderly: a guideline. Obes Facts. 2012;(3):460-83.

5. Kim TN, Park MS, Yang SJ, Yoo HJ, Kang HJ, Song W, et al. Prevalence and determinant factors of sarcopenia in patients with type 2 diabetes: the Korean Sarcopenic Obesity Study (KSOS). Diabetes Care. 2010;33(7):1497-9.

6. Lim S, Kim JH, Yoon JW, Kang SM, Choi SH, Park YJ et al. Sarcopenic obesity: prevalence and association with metabolic syndrome in the Korean Longitudinal Study on Health and Aging (KLoSHA). Diabetes Care. 2010;33:1652-54.

7. Stephen WC, Janssen I. Sarcopenic-obesity and cardiovascular disease risk in the elderly. J Nutr Health Aging. 2009;13:460-66.

8. Chien MY, Kuo HK, Wu YT. Sarcopenia, cardiopulmonary fitness, and physical disability in community-dwelling elderly people. Phys Ther. 2010;90(9):1277-87.

9. Li Z, Heber D. Sarcopenic obesity in the elderly and strategies for weight management. Nutr Rev. 2012;70(1):57-64.

10. LaMonte MJ, Blair SN. Physical activity, cardiorespiratory fitness, and adiposity: contributions to disease risk. Curr Opin Clin Nutr Metab Care. 2006;9:540-46. 
11. Drøyvold WB, Nilsen TI, Krüger O, Holmen TL, Krokstad S, Midthjell K, et al. Change in height, weight and body mass index: Longitudinal data from the HUNT Study in Norway. Int J Obes (Lond). 2006;30(6):935-9.

12. Han TS, Tajar A, Lean ME. Lean Obesity and weight management in the elderly. Br Med Bull. 2011;97:169-96.

13. Kelles SMB, Diniz MFHS, Machado CJ, Barreto SM. Perfil de pacientes submetidos à cirurgia bariátrica, assistidos pelo Sistema Único de Saúde do Brasil: revisão sistemática. Cad Saúde Pública. 2015; 31(8):1587-1601.

14. Sturm R, Hattori A. Morbid obesity rates continue to rise rapidly in the US. Int J Obes; 2013; 37(6):889-891.

15. Bloomberg RD, Fleishman A, Nalle JE, Herron DM, Kini S. Nutritional deficiencies following bariatric surgery: what have we learned? Obes Surg. 2005;15:145-54.

16. Brandão CMA, Camargos BM, Zerbini CA, Plapler CA, Mendonça LMC, Albergaria B, et al. Posições oficiais 2008 da Sociedade Brasileira de Densitometria Clínica (SBDens). Arq Bras endocrinol metab. 2009;53(1):107-12.

17. Newman A, Kupelian V, Visser M, Simonsick E, Goodpaster B, Nevitt M, et al. Sarcopenia: alternative definitions and association with lower extremity function. J Am Geriatr Soc. 2003;51:1602-9.

18. Oliveira RJ, Bottaro M, Júnior JT, Farinatti PT, Bezerra LA, Lima RM. Identification of sarcopenic obesity in postmenopausal women: a cutoff proposal. Braz J Med Biol Res. 2011;44(11):1171-6.

19. O'Brien PE, McPhail T, Chaston TB, Dixon JB. Systematic review of medium-term weight loss after bariatric operations. Obes. Surg. 2006;16:1032-40.

20. Larsson I, Lissner L, Näslund I, Lindroos AK. Leisure and occupational physical activity in relation to body mass index in men and women. Scand J Nutr. 2004;48(4):165-72.

21. Sjöström L, Lindroos AK, Peltonen M, Bouchard C, Carlsson B, Dahlgren S, et al. Lifestyle, diabetes, and cardiovascular risk factors 10 years after bariatric surgery. $\mathrm{N}$ Engl J Med. 2004;351:2683-93.

22. Cohen J. Statistical power analysis for the behavioral sciences. Erlbaum, Hillsdale, 1988.

23. Freire RH, Borges MC, Alvarez-Leite JI, Toulson Davisson Correia MI. Food quality, physical activity, and nutritional follow-up as determinant of weight regain after Rouxen-Y gastric bypass. Nutrition. 2012;28(1):53-8.

24. Mechanick J I. et al. AACE/TOS/ASMBS Guidelines, Surg Obes Relat Dis 2008, 4 (suppl 1): S109-S184.

25. Silver HJ, Torquati A, Jensen GL, Richards WO. Weight, dietary and physical activity behaviors two years after gastric bypass. Obes Surg. 2006;16(7):859-64.

26. Han TS, Wu FC, Lean ME. Obesity and weight management in the elderly: a focus on men. Best Pract Res Clin Endocrinol Metab. 2013;27(4):509-25.

27. Jacobi D., Ciangura C, Couet C, Oppert JM. Physical activity and weight loss following bariatric surgery Obes Rev. 2011;12(5):366-77.

28. Antonini VDS, Hintze LJ, Silva DF, Hermoso DM, Carolino IDR, Nardo Junior N. Comportamentos associados à manutenção dos resultados após cirurgia bariátrica. Medicina (USP.FMRP). 2014;47(2):149-56.

CORRESPONDING AUTHOR

LUZIA JAEGER HINTZE

lujhintze@hotmail.com

ljaeg051@uottawa.ca
University of Ottawa, School of Human

Kinetics 200 Lees, Room E033, Ottawa,

ON K1N 6N5 Canada

Tel: $+1(613) 9140634$
RECEIVED

$02 / 06 / 2016$

APPROVED $24 / 08 / 2016$ 